Meta

Journal des tradlucteurs

Translators' Journal

\title{
Dictionnaire du français contemporain, Paris, Larousse, 1967, 1252 p. [58 F].
}

Volume 12, numéro 2, juin 1967

URI : https://id.erudit.org/iderudit/017765ar

DOI : https://doi.org/10.7202/017765ar

Aller au sommaire du numéro

Éditeur(s)

Les Presses de l'Université de Montréal

ISSN

0026-0452 (imprimé)

1492-1421 (numérique)

Découvrir la revue

Citer ce compte rendu

(1967). Compte rendu de [Dictionnaire du français contemporain, Paris, Larousse, 1967, 1252 p. [58 F].] Meta, 12(2), 66-66.

https://doi.org/10.7202/017765ar

Ce document est protégé par la loi sur le droit d'auteur. L'utilisation des services d'Érudit (y compris la reproduction) est assujettie à sa politique d'utilisation que vous pouvez consulter en ligne.

https://apropos.erudit.org/fr/usagers/politique-dutilisation/
Cet article est diffusé et préservé par Érudit.

Érudit est un consortium interuniversitaire sans but lucratif composé de l'Université de Montréal, l'Université Laval et l'Université du Québec à Montréal. Il a pour mission la promotion et la valorisation de la recherche. https://www.erudit.org/fr/ 
- , The Story of Language, Toronto, New American Library of Canada, 1966. $[\$ 0.95]$

Postman, N. and H. Damon, Language and Reality, New York, Holt, 1966. $[\$ 3.60]$

Rafroidi, P., M. Plarsant et D. Shott, Manuel de l'angliciste, t. I, Paris, Office central de librairie, 1966. [26 F]

Singh, Jargjit, Great Ideas in Information Theory, Language and Cybernetics, New York, Dover Publications Ine., 1966. [\$2.]

Sulger, F., Précis de grammaire anglaise, Paris, Dunod, 1966, 72 p. [4,60 F]

Sutherland, Ronald et Cormac Gérard CAPpon, l'Esprit de la langue anglaise, Toronto, W. J. Gage, 1966, 282 p. [\$3.50]

\section{INTERPRÉTATION}

Bacon, W., The Art of Interpretation, New York, Holt, 1966. [\$6.95]

Campbell, P. N., Oral Interpretation, New York, Maemillan, 1966. [\$1.75]

Geeting, Baxter M., Interpretation for Our Time, London, Brown W. C., 1966, 324 p. $[\$ 5.75]$

Paul A. Horguelin

Dictionnaire du français contemporain, Paris, Larousse, 1967, 1252 p. [58 F].

Le Dictionnaire du français contemporain est un dietionnaire de la langue usuelle qui garantit au lecteur que tous les mots étudiés sont employés actuellement, tant dans la langue écrite que parlée. Les quelque 25000 termes retenus comprennent les termes techniques qui ont une large diffusion, tandis que les mots, les expressions et les eonstructions appartenant à la langue écrite archaïque ont été systématiquement éliminés.

À côté de l'ordre alphabétique, l'ouvrage offre au lecteur une présentation raisonnée $d u$ vocabulaire par familles de mots (regroupements), chaque fois qu'il existe entre eux un rapport de forme ou de signification (ex.: os, ossature, osseux, ossu, s'ossifier, ossements, osselets, ossuaire, désosser, etc.). En revanche, un système de dégroupements distingue, sous forme d'articles séparés et numérotés, les mots d'orthographe identique mais de sens totalement étrangers (ex.: altérer, dans le sens de « donner soif 》, a été séparé de altérer, « modifier l'état normal »).

Le dictionnaire classe les significations d'un mot d'après les constructions grammaticales : nature du sujet ou du complément, place de l'adjectif. Grâce à une multiplicité d'exemples, tous les emplois des termes de la langue sont donnés avec les nuances qui les distinguent. Il est aussi un dictionnaire des synonymes et des contraires avec leurs différences de sens et d'emploi, un dictionnaire des niveaux de langue (familier, populaire, argotique, langue soignée, littéraire, etc.), un dictionnaire de prononciation utilisant l'alphabet phonétique international et, enfin, un dictionnaire de grammaire muni de 90 tableaux de conjugaisons, de suffixes, de préfixes et de remarques diverses.

(Communiqué) 